\title{
Attention to the eyes and fear-recognition deficits in child psychopathy
}

\author{
MARK R. DADDS, YAEL PERRY, DAVID J. HAWES, SABINE MERZ, \\ ALISON C. RIDDELL, DAMIEN J. HAINES, EMEL SOLAK \\ and AMALI I. ABEYGUNAWARDANE
}

\begin{abstract}
Summary The ability to recognise fear is impaired in people with damage to the amygdala and, interestingly, in adult psychopathy. Here we confirm that deficits in recognising fear exist in children with psychopathic traits. We show for the first time that, as with patients with amygdala damage, this deficit can be temporarily corrected by simply asking them to focus on the eyes of other people. These data support models of psychopathy that emphasise specific dysfunction of the amygdala and suggest an innovative approach for intervening early in the development of psychopathy.
\end{abstract}

\section{Declaration of interest None. \\ Funding detailed in Acknowledgements.}

Deficits in fear recognition occur in both psychopathy (Hare, 1995; Blair, 2003) and patients with amygdala damage (Davis \& Whalen, 2001; Adolphs et al, 2005) suggesting a role for amygdala dysfunction in psychopathy. Recently, Adolphs et al (2005) showed that deficits in fear recognition associated with amygdala dysfunction are driven by lack of attention to other people's eyes, and could be overcome by instructing subjects to attend to the eyes. No study has tested whether these attentional processes occur in the fear-recognition problems characteristic of psychopathy. A positive finding might have enormous potential for understanding the development of the most severe forms of antisocial behaviour.

Whereas it may be naïve to think that deficits in fear recognition could account for antisocial behaviour seen in adult psychopathy, such deficits could have a powerful influence during critical periods of child development. Fear recognition necessitates understanding that other people are sentient, typically described as a theory of mind (Skuse, 2003), in order to discern the source of threat from the direction of the other's gaze (Emery, 2000). A theory of mind is necessary for the development of empathy; amygdala damage is associated with deficits in theory of mind development (Shaw et al, 2004); and children lacking this skill are less likely to develop healthy emotional connections or to benefit from the subtleties of caregiver discipline associated with the development of a conscience (Hughes et $a l, 2000)$. Thus, we were particularly interested in testing whether fear-recognition deficits occur and could be modified in children with psychopathic traits.

\section{METHOD}

This study tested the relationships of fear recognition and eye gaze to psychopathic traits (callous-unemotional traits and antisocial behaviour) in community samples of children and adolescents. Psychopathic traits measured in these samples are prognostic of negative outcomes (Dadds et al, 2005), have high genetic loadings (Viding et al, 2005), and have the advantage of not being confounded by comorbidity problems that characterise clinical and forensic samples. We hypothesised that:

(a) callous-unemotional traits would be uniquely associated with poorer recognition of fear in a free-gaze condition;

(b) highly callous-unemotional children would improve to normal levels when instructed to attend to the eyes;

(c) in a mouth-gaze condition, the highly callous-unemotional children would return to their previous levels.

The studies were conducted in schools in Sydney, Australia. The first experiment included 33 boys, ranging in age from 8 to 15 years (mean 12.07, s.d.=1.91); the second included 65 boys, ranging in age from 9 to 17 years (mean 13.2, s.d. $=1.87$ ). Both samples were from middle- to uppermiddle-class backgrounds. Means and standard deviations for callous-unemotional and antisocial behaviour were consistent with normative samples from Australia (Dadds et al, 2005).

Callous-unemotional traits and antisocial behaviour were measured as described in Dadds et al (2005). Parent and child scores were combined using a highestscore counts method. Accuracy of emotion recognition was measured using the University of New South Wales Facial Emotion Task (Dadds et al, 2004), in which happiness, sadness, anger, disgust, fear or a neutral expression is displayed by four adult faces. Testing occurred in school classes. Emotions were presented in a random order for $2 \mathrm{~s}$ each. Participants recorded the emotion portrayed from a list of six emotions. In study 2 , the faces were repeated in two further blocks. In blocks 2 and 3, participants were instructed to focus on the eyes and the mouth, respectively, of the display faces. The order of the blocks was chosen because free gaze needed to be first in order to avoid contamination by the later instructions. The look-at-the-eyes condition was scheduled next and the look-at-the-mouth condition last, so that any practice effects producing an improvement in accuracy over time would run counter to the experimental hypothesis that eye gaze would produce the highest accuracy.

\section{RESULTS}

Partial correlations of callous-unemotional traits and antisocial behaviour to accuracy of emotion recognition are shown in Fig. 1a. Antisocial behaviour was associated with poorer recognition of neutral faces $(r=-0.43, P<0.004)$, where neutral faces were most often mistakenly rated as angry. This finding is consistent with the hostilitybias model in which antisocial people are thought to over-interpret hostility in other people (Dodge \& Pettit, 1993). As hypothesised, callous-unemotional scores were uniquely associated with poor recognition of fearful faces $(r=-0.52, P<0.0001)$. The most common errors were to rate fear as neutral emotion or disgust. In the second experiment in the free-gaze condition, we replicated the finding that callous-unemotional scores were negatively correlated with fear accuracy $(r=-0.36, \quad P<0.01)$. The correlation dropped to $r=0.05$ in the eye-gaze condition, but was again significant in the mouth-gaze condition, $r=-0.24, P<0.05$. 

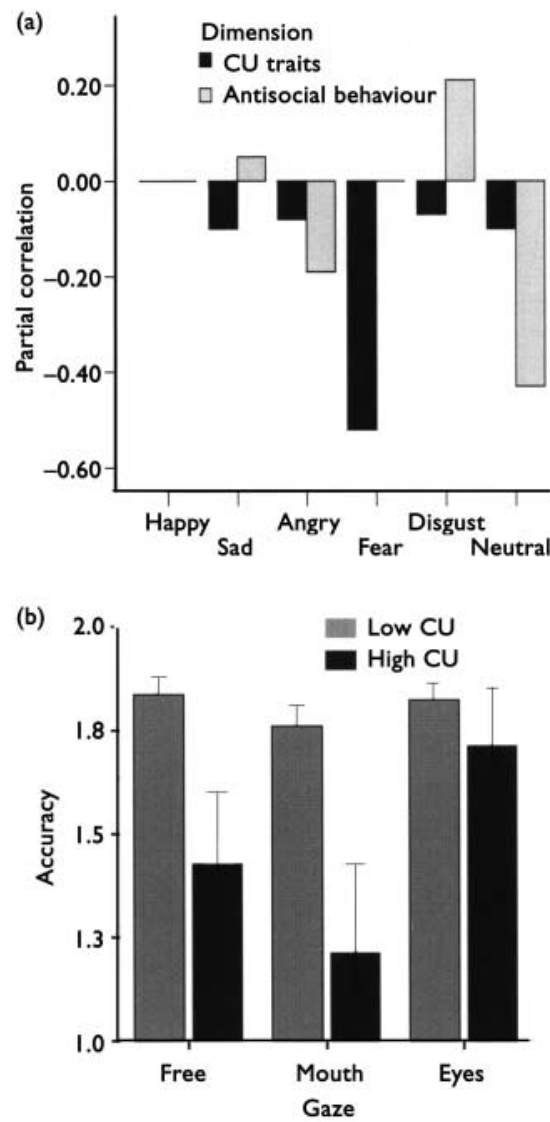

Fig. I. (a) Partial correlations of antisocial (controlling for callous-unemotional (CU) traits) and $\mathrm{CU}$ traits (controlling for antisocial) with accuracy of recognition of the six emotions for boys in study I. (b) Mean accuracy for facial fear recognition for boys high and low on $\mathrm{CU}$ traits under three gaze conditions: no instruction, instruction to focus on eyes, instruction to focus on mouth. Significant interaction between gaze and $\mathrm{CU}$ category, $F(2,55)=5.149, P=0.009$. Error bars represent standard errors of the means.

Thus, high callous-unemotional scores were associated with poorer fear recognition except when participants were instructed to look at the eyes. The mean accuracy scores of fear recognition for boys across the three gaze conditions for the sample split into high callous-unemotional (top 25\%) and lowaverage callous-unemotional groups are shown in Fig. 1b. Clearly, highly callousunemotional children are substantially poorer at recognising fear unless specifically instructed to look at the eyes. Direction of gaze made no difference to accuracy rates in low callous-unemotional children.

MARK R. DADDS, PhD, YAEL PERRY, BPsych, DAVID J. HAWES, PhD, SABINE MERZ, BA, ALISON C. RIDDELL, BPsych, DAMIEN J. HAINES, BPsych, EMEL SOLAK, BPsych, AMALI I. ABEYGUNAWARDANE, BPsych, University of New South Wales, Sydney, Australia

Correspondence: Dr Mark R. Dadds, School of Psychology, University of New South Wales, Sydney, NSW 2052, Australia.Email: m.dadds@unsw.edu.au

(First received 9 October 2005, final revision 15 December 2005, accepted 31 January 2006)

\section{DISCUSSION}

These results show that antisocial behaviour and callous-unemotional traits are associated with very different emotionrecognition problems in young males. Specifically, antisocial behaviour is uniquely associated with a tendency to oversee hostility, and callous-unemotional traits, the affective aspect of psychopathy, are uniquely related to poor recognition of fearful expressions. The current study shows that this deficit in fear recognition is in part owing to visual neglect of the eye region of other people's faces, as with amygdala-damaged patients (Adolphs et $a l, 2005)$, and can be temporarily reversed by directing attentional focus to the eye region of other people. Although this study is the first to demonstrate this effect, we note that Richell et al (2003) found that psychopathic individuals could identify facial emotions using stimulus faces that were truncated to include only information from the eye region.

Although they require replication in larger samples containing more extremes of the psychopathy traits, these findings indicate that emotion-recognition problems in psychopathy are owing in part to a failure to direct attention to the emotionally significant aspects of the environment. This may have wide-reaching implications for understanding and intervening with high-risk children at developmentally sensitive periods. We argue that these attentional processes will be of critical importance in the early years of life, when responsiveness to normal discipline practices will depend in part on the ability to recognise the emotional states of caregivers. Further, the ability to recognise fear in other people may be a specific marker of the ability to develop theory of mind during the developmental stage that is critical for learning that other people are sentient, feeling organisms: a skill that is needed in order to treat others accordingly.

\section{ACKNOWLEDGEMENTS}

This research was supported by a National Health and Medical Research Council of Australia Project Grant to M.D.

\section{REFERENCES}

Adolphs, R., Gosselin, F., Buchanan, T.W., et al (2005) A mechanism for impaired fear recognition after amygdala damage. Nature, 433, 68-72.

Blair, R. J. R. (2003) Neurobiological basis of psychopathy. British Journal of Psychiatry, 182, 5-7.

Dadds, M. R., Hawes, D. \& Merz, S. (2004) The UNSW Facial Emotion Task. Sydney: University of New South Wales.

Dadds, M. R., Fraser, J., Frost, A., et al (2005) Disentangling the underlying dimensions of psychopathy and conduct problems in childhood: a community study. Journal of Consulting and Clinical Psychology, 73, 400-4I0.

Davis, M. \& Whalen, P. J. (200I) The amygdala: vigilance and emotion. Molecular Psychiatry, 6, 3-34.

Dodge, K. A. \& Pettit, G. S. (1993) A biopsychosocia model of the development of chronic conduct problems in adolescence. Developmental Psychology, 39, 349-37I.

Emery, N. J. (2000) The eyes have it: the neuroethology, function and evolution of social gaze. Neuroscience and Biobehavioral Reviews, 24, 581-604.

Hare, R. D. (1995) Psychopathy: theory, research and implications for society. An introduction. Issues in Criminological and Legal Psychology, 24, 4-5.

Hughes, C., White, A., Sharpen, J., et al (2000) Antisocial, angry, and unsympathetic: 'hard-to-manage' preschoolers' peer problems and possible cognitive influences. Journal of Child Psychology \& Psychiatry, 4I, 169-179.

Richell, R. A., Mitchell, D. G.V., Newman, C., et al (2003) Theory of mind and psychopathy: can psychopathic individuals read the 'language of the eyes'? Neuropsychologia, 4I, 523-526.

Shaw, P., Lawrence, E. J., Radbourne, C., et al (2004) The impact of early and late damage to the human amygdala on 'theory of mind' reasoning. Brain, 127, 1535-1548.

Skuse, D. (2003) Fear recognition and the neural basis of social cognition. Child and Adolescent Mental Health, 8 $50-60$.

Viding, E., Blair, R. J., Moffitt, T. E., et al (2005) Evidence of substantial genetic risk for psychopathy in 7-year-olds. Journal of Child Psychology and Psychiatry, 46 592-597. 